\title{
Erratum: Highly thermal-stable ferromagnetism by a natural composite
}

Tianyu Ma, Junming Gou, Shanshan Hu, Xiaolian Liu, Chen Wu, Shuai Ren, Hui Zhao, Andong Xiao, Chengbao Jiang, Xiaobing Ren \& Mi Yan

Nature Communications 8:13937 doi: 10.1038/ncomms13937 (2017); Published 18 Jan 2017; Updated 21 Mar 2017

The Author Mi Yan was incorrectly omitted from the list of corresponding Authors in the PDF of this Article, and the author Tianyu Ma was incorrectly listed as a corresponding author; the HTML version of the paper was correct from the time of publication. The correct information for correspondence is: 'Correspondence and requests for materials should be addressed to X.R. (email: ren.xiaobing@nims.go.jp) or to M.Y. (email: mse_yanmi@zju.edu.cn).’

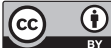

This work is licensed under a Creative Commons Attribution 4.0 International License. The images or other third party material in this article are included in the article's Creative Commons license, unless indicated otherwise in the credit line; if the material is not included under the Creative Commons license, users will need to obtain permission from the license holder to reproduce the material. To view a copy of this license, visit http://creativecommons.org/licenses/by/4.0/

(C) The Author(s) 2017 